\title{
More optimism, less pain! The influence of generalized and pain-specific expectations on experienced cold- pressor pain
}

Citation for published version (APA):

Hanssen, M. M., Vancleef, L. M. G., Vlaeyen, J. W. S., \& Peters, M. L. (2014). More optimism, less pain! The influence of generalized and pain-specific expectations on experienced cold-pressor pain. Journal of Behavioral Medicine, 37(1), 47-58. https://doi.org/10.1007/s10865-012-9463-8

Document status and date:

Published: 01/01/2014

DOI:

10.1007/s10865-012-9463-8

Document Version:

Publisher's PDF, also known as Version of record

Document license:

Taverne

Please check the document version of this publication:

- A submitted manuscript is the version of the article upon submission and before peer-review. There can be important differences between the submitted version and the official published version of record.

People interested in the research are advised to contact the author for the final version of the publication, or visit the DOI to the publisher's website.

- The final author version and the galley proof are versions of the publication after peer review.

- The final published version features the final layout of the paper including the volume, issue and page numbers.

Link to publication

\footnotetext{
General rights rights.

- You may freely distribute the URL identifying the publication in the public portal. please follow below link for the End User Agreement:

www.umlib.nl/taverne-license

Take down policy

If you believe that this document breaches copyright please contact us at:

repository@maastrichtuniversity.nl

providing details and we will investigate your claim.
}

Copyright and moral rights for the publications made accessible in the public portal are retained by the authors and/or other copyright owners and it is a condition of accessing publications that users recognise and abide by the legal requirements associated with these

- Users may download and print one copy of any publication from the public portal for the purpose of private study or research.

- You may not further distribute the material or use it for any profit-making activity or commercial gain

If the publication is distributed under the terms of Article $25 \mathrm{fa}$ of the Dutch Copyright Act, indicated by the "Taverne" license above, 


\title{
More optimism, less pain! The influence of generalized and pain-specific expectations on experienced cold-pressor pain
}

\author{
Marjolein M. Hanssen • Linda M. G. Vancleef • \\ Johan W. S. Vlaeyen · Madelon L. Peters
}

Received: March 6, 2012/Accepted: October 9, 2012/Published online: October 23, 2012

(C) Springer Science+Business Media New York 2012

\begin{abstract}
Accumulating evidence suggests that dispositional optimism might be a protective factor against experiencing pain. The current paper presents two studies investigating the association between dispositional optimism and experimental pain. Moreover, the influence of pain-specific expectations on this association is investigated. In Study 1, mediation of pain-specific expectations in the relation between dispositional optimism and pain was hypothesized. Expected and experienced pain ratings were obtained from 66 healthy participants undergoing a cold pressor tolerance task. In Study 2, the moderating effect of dispositional optimism on the association between induced pain expectations and pain reports was studied in 60 healthy participants undergoing a 1-min cold pressor task. Both studies controlled for individual differences in fear of pain. Significant associations between dispositional optimism and pain ratings were found in both studies, although the exact time point of these associations differed. Subscale analyses revealed that only the pessimism subscale contributed significantly to these findings. We found no evidence for hypothesized mediation and moderation effects. Alternative explanations for the optimism-pain association are discussed.
\end{abstract}

Keywords Dispositional optimism - Experimental pain . Expectation $\cdot$ Cold pressor $\cdot$ Positive psychology

M. M. Hanssen $(\bowtie)$. L. M. G. Vancleef .

J. W. S. Vlaeyen · M. L. Peters

Department of Clinical Psychological Science,

Maastricht University, Maastricht, The Netherlands

e-mail: m.hanssen@maastrichtuniversity.nl

J. W. S. Vlaeyen

Research Group Health Psychology, University of Leuven,

Leuven, Belgium

\section{Introduction}

Chronic pain is an important health problem, profoundly impacting on millions of people's lives. In the past decades, research has successfully identified important psychological risk factors for the transition of acute to chronic pain (Linton \& Shaw, 2011). For instance the fear-avoidance model of pain, one of the most influential cognitive-behavioral models nowadays, describes how a negative spiral of catastrophic appraisals, pain-related fear and avoidance can lead to or maintain pain-related disability (Leeuw et al., 2007; Vlaeyen \& Linton, 2000, 2012). Despite major advances in understanding and treating pain, an exclusive focus on risk factors might fail to capture the full complexity of the pain experience and its determinants.

Although the attention is growing, comparably little effort has been put into the systematic study of resilience factors for pain so far. Disentangling what protects people from getting caught up in the negative spiral towards disability can lead to new possibilities for therapeutic interventions. Several studies have already indicated that higher levels of resilience in pain patients are related to various positive outcomes, such as lower levels of daily pain catastrophizing (Ong et al., 2010), less health care and medication use (Karoly \& Ruehlman, 2006), better adjustment to early confrontation with pain (Wright et al., 2008) and better psychological adjustment to chronic pain (Mangelli et al., 2002; Ramirez-Maestre et al., 2012a; Sturgeon \& Zautra, 2010). In the past decades, dispositional optimism has been proposed as one potential resilience factor for pain. However, few studies have studied its influence on pain using an experimental design or tried to unravel the underlying mechanisms. 
Dispositional optimism and pain

There is a vast amount of research relating dispositional optimism, defined as generalized positive outcome expectancy, to increased psychological and physical well-being (Rasmussen et al., 2009; Scheier \& Carver, 1985, 1992). More recently, the role of dispositional optimism in relation to the experience of pain has been acknowledged. First, dispositional optimism may be related to better wellbeing despite pain. In chronic pain patients, dispositional optimism was found to be related to increased feelings of control, the use of more active coping strategies and better functional performance (Affleck et al., 2001; Brenes et al., 2002; Novy et al., 1998; Ramirez-Maestre et al., 2012b). Second, optimists may be less sensitive to the experience of pain, which may protect them from the transition of acute to chronic pain. Survey studies in community samples indicated that the prevalence of various types of pain complaints is lower in more optimistic people (Achat et al., 2000; Sipila et al., 2006). Reversed causality cannot be excluded in these studies but other studies demonstrated that dispositional optimism may predict subsequent pain, for instance after surgical intervention (Mahler \& Kulik, 2000; Powell et al., 2012). In addition, experimental pain paradigms have found higher ischemic pain tolerance (Costello et al., 2002), lower pain reports and lower cardiovascular reactivity during a cold pressor task in optimists as compared to pessimists (Geers et al., 2008).

Pain-specific expectations and pain

Generalized expectations are not the only psychological factors that have been related to pain outcomes. The influence of pain-specific expectations on the subjective experience of pain is well documented. Expectation was identified as one of the core mechanisms underlying placebo analgesia (Benedetti et al., 2003). The mere suggestion that a strong versus weak pain stimulus will be given alters subsequent pain ratings (Colloca et al., 2008; Keltner et al., 2006; Lorenz et al., 2005). Interestingly, painspecific expectations not only influence pain reports, but also the neural processes that underlie nociception and pain-relief (Colloca et al., 2008; Lorenz et al., 2005; Mirsky, 2007).

Disentangling the relationship between generalized and pain-specific expectations

It may be proposed that pain-specific expectations might be a mediating factor in the link between dispositional optimism and pain. Optimists typically expect positive outcomes in a variety of situations (Scheier \& Carver, 1985). Possibly optimists' general expectancy of positive outcomes extends to pain-specific expectations, thereby diminishing pain-sensitivity and avoidance behavior.

It has also been suggested that dispositional optimism interacts with situational factors in determining pain sensitivity (Geers et al., 2008, 2010). Especially under conditions where pain expectancies are manipulated (e.g. placebo or nocebo suggestions) the influence of dispositional optimism may become apparent. Previous studies found evidence for the idea that optimists may be more sensitive to placebo suggestions (Geers et al., 2007, 2010; Morton et al., 2009), while pessimists are more likely to follow a nocebo suggestion (Geers et al., 2005). This would mean that pain-specific expectancies might only lead to lower reported pain intensity when dispositional optimism is high.

The present research

In two separate studies we seek to confirm and understand the relationship between dispositional optimism, painspecific expectations and experimental pain sensitivity.

Study 1 was designed to test the mediation model in which dispositional optimism is expected to lead to lower reported pain intensity and higher tolerance for cold pressor pain through its influence on pain-specific expectations. Study 2 tests the moderation model, in which dispositional optimism is hypothesized to moderate the effects of induced pain expectations on experienced pain. Because previous studies found that the optimism and pessimism subscales of the Life Orientation Test may differentially predict various health outcomes (Brenes et al., 2002; Robinson-Whelen et al., 1997), we analysed the results using both the total scale score as well as the subscale scores. In addition, both studies controlled for the influence of individual differences in fear of pain. Numerous studies have reported that pain-related fear is associated with increased pain expectations/sensitivity (Arntz et al., 1990; Roelofs et al., 2004; Vlaeyen \& Linton, 2000).

\section{Study 1}

Methods

\section{Participants}

Sixty-six students (51 female; $M_{\text {age }}=21.41 ; S D=2.36$ ) between the age of 18 and 35 participated in this study. Students were recruited by flyers at Maastricht University and participated in exchange for course credit or financial compensation. Exclusion criteria were non-native Dutch speaking, prior experience with the cold pressor task, high blood pressure or cardiovascular problems and current 
acute or chronic pain complaints. These criteria were verbally checked prior to scheduling.

\section{Apparatus}

For the cold pressor task, a Julabo ED-19A open heating bath circulator with Plexiglas bath tank was used. Dimensions of the bath opening (width $\times$ length/depth) were $36 \times 30 / 15 \mathrm{~cm}$. Circulated water was maintained at a temperature of $5{ }^{\circ} \mathrm{C}$ with a stability of $\pm .03{ }^{\circ} \mathrm{C}$. A unit containing water at room temperature $\left(20^{\circ} \mathrm{C}\right)$ was positioned next to the cold pressor apparatus.

\section{Measures}

Dispositional optimism: life orientation test revised (LOT$R$ ) Dispositional optimism, as a generalized positive outcome expectancy, was measured using the LOT-R (Scheier et al., 1994). The LOT-R consists of 3 positively and 3 negatively framed items, as well as 4 filler items. All items are scored on a 5-point scale, ranging from 1 (= strongly agree) to 5 (= strongly disagree). In line with the original conceptualisation, the total score of the LOT-R was used to represent a person's level of dispositional optimism. In addition, optimism and pessimism subscale scores were calculated by summing the positive and negative items respectively. A Cronbach's alpha of .79 for the LOT-R total score indicates that the internal consistency is satisfactory in this study. Cronbach's alpha for the optimism and pessimism subscale are .65 and .78 respectively.

Fear of pain: fear of pain questionnaire short form (FPQ$S F$ ) The FPQ-SF (Asmundson et al., 2008) was used to measure fear of pain. The FPQ-SF consists of 20 items describing situations causing minor, severe and medical pain. Participants indicate how fearful they are for the pain in the described situations on a scale from 1 (= not fearful at all) to 5 (= extremely fearful). The total score of the FPQ-SF was used in this study. In this study, internal consistency of the FPQ-SF is good with a Cronbach's alpha of .87 .

Expected/experienced pain intensity ratings and pain tolerance Pain-specific expectation was measured with a visual analogue scale (VAS). The question 'How much pain do you expect during the cold pressor task?' was followed by a $100 \mathrm{~mm}$ horizontal line, with 'no pain at all' at one end and 'extreme pain' at the other.

Experienced pain was assessed by verbal pain intensity ratings on a scale from 0 (=no pain at all $)$ to 100 (= extreme pain) at several moments during the cold pressor task. In addition, pain tolerance (i.e. time from the start of immersion until hand withdrawal) was recorded. The maximum tolerance time was set at $300 \mathrm{~s}$.

\section{Procedure}

The study was approved by the institutional review board and informed consent was obtained from each participant at arrival in the lab. After providing informed consent, participants received verbal instructions about the procedure. Before starting the cold water immersion, participants rated the expected pain intensity on the VAS. Next, to ensure equal skin temperature before the cold pressor task, participants immersed their non-dominant hand in a container with water at room temperature $\left(20^{\circ} \mathrm{C}\right)$ for the duration of $1 \mathrm{~min}$. This immersion was immediately followed by the cold water immersion $\left(5^{\circ} \mathrm{C}\right)$. Participants received the instruction to immerse their hand in the cold water container 'for as long as they could'. They were instructed to immerse their hand up to the level of the wrist line in the water container, thereby horizontally stretching out their hand without resting it on the bottom of the container. At 5 and at $20 \mathrm{~s}$ after the start of the immersion the researcher prompted participants to give a verbal pain intensity rating (during immersion ratings). The experimenter wrote down the participants' ratings and prevented the immersion from exceeding the preset maximum time by instructing participants to withdraw their hand from the water when $5 \mathrm{~min}$ had elapsed. Right after participants extracted their hand from the water, they were prompted to indicate how much pain they experienced just before they withdrew their hand from the cold water (end immersion rating). At $20 \mathrm{~s}$ post-immersion, participants were asked to rate their pain intensity again (post-immersion rating). At the end of the session, participants completed the trait questionnaires (LOT-R and FPQ-SF) on the computer.

\section{Statistical analyses}

Mean scores and standard deviations of the main variables of this study (i.e. dispositional optimism (total score), optimism/pessimism (subscales), fear of pain, expected and experienced pain intensity ratings and pain tolerance time) were calculated. The strength and direction of the linear relation between these variables were estimated by Pearson correlation coefficients.

To test whether pain-specific expectations mediated the relation between dispositional optimism and pain experience, multiple regression analyses were performed following the guidelines of Baron and Kenny (1986) (see Fig. 1). Because the relation of dispositional optimism and painspecific expectations with early or late pain may differ, three 
Hypothesized mediation model.

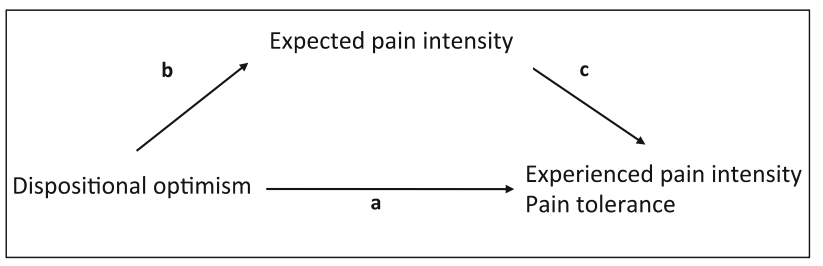

Fig. 1 Hypothesized mediation model

separate mediation analyses were performed for pain during $\left(20 \mathrm{~s} \mathrm{rating}^{1}\right)$, at the end of the immersion and $20 \mathrm{~s}$ postimmersion. In addition, a mediation analysis for pain tolerance was conducted. In a first regression analysis (path a), it was tested whether the predictor variable (dispositional optimism) was correlated with the outcome variable (pain tolerance/experienced pain intensity). Second, path $\mathrm{b}$ was examined to determine if the predictor variable (dispositional optimism) was significantly correlated with the mediator (expected pain intensity). Third, the outcome variable (pain tolerance/experienced pain intensity) was regressed on the mediator (expected pain intensity), whilst controlling for the predictor variable (dispositional optimism) to test path c. To confirm the mediation hypothesis, it was examined if in this latter regression analysis, the mediator (pain expectancy) was significantly correlated with the pain related outcome measures and whether the effect of the predictor variable (dispositional optimism) disappeared or was reduced, thus showing either full or partial mediation. Fear of pain was controlled for in all the regression analyses. Because experienced pain intensity at the end and postimmersion may be influenced by pain tolerance, this variable was controlled for in the analyses of the end and postimmersion pain ratings. All the regression analyses were repeated with the pessimism and optimism subscale instead of the total score of dispositional optimism in order to detect possible differential results.

\section{Results}

\section{Descriptives and intercorrelations of main variables}

Table 1 shows the mean scores, standard deviations and intercorrelations of dispositional optimism (total score), optimism/pessimism (subscales), fear of pain, expected and experienced pain. The mean cold pressor pain tolerance was $195.29 \mathrm{~s} \quad(S D=108.13 \mathrm{~s})$. Thirty participants $(45.5 \%)$ immersed their hand for $300 \mathrm{~s}$, the preset toler-

\footnotetext{
${ }^{1}$ For reasons of conciseness, all analyses will be reported for the $20 \mathrm{~s}$ during immersion rating. Analyses with the $5 \mathrm{~s}$ measure did not yield significantly different results and can be obtained from the corresponding author.
}

ance limit. No significant differences in expected pain $(t=1.07 ; p>.05)$, dispositional optimism $(t=-.61$; $p>.05)$ or fear of pain $(t=1.14 ; p>.05)$ were found between participants who did and did not reach the preset tolerance time.

The simple correlations between the study variables showed that dispositional optimism correlated significantly with experienced pain intensity during immersion. On subscale level, the pessimism, but not the optimism subscale was found to correlate with experienced pain. Expected pain intensity correlated significantly with each of the experienced pain intensity ratings. Fear of pain was not significantly related to any of the other variables. ${ }^{2}$

\section{Dispositional optimism, expected pain and pain experience: examining mediation}

First, experienced pain intensity ratings and pain tolerance were regressed on dispositional optimism and control variable(s). Dispositional optimism was a significant predictor of pain intensity during immersion $(\beta=-.27$; $t=-2.23 ; p<.05)$. Dispositional optimism also contributed significantly $(\beta=-.25 ; t=-2.59 ; p<.05)$ to the prediction of pain intensity at the end of the immersion together with pain tolerance as a covariate $(\beta=-.64$; $t=-6.71 ; p<.001)$, but not to pain intensity postimmersion $(\beta=-.20 ; t=-1.65 ; p>.05)$. Subscale analyses showed that only the pessimism subscale is significantly related to pain intensity during immersion $(\beta=.29 ; t=2.38 ; p<.05)$ and pain intensity at the end of the immersion $(\beta=.27 ; t=2.80 ; p<.05)$. Pain tolerance was not significantly predicted by dispositional optimism, optimism and pessimism subscales or fear of pain.

Second, a regression analysis testing path $\mathrm{b}$ showed that neither dispositional optimism $(\beta=-.02 ; t=-.19$; $p>.05)$ nor fear of pain $(\beta=.12 ; t=.92 ; p>.05)$ contributed significantly in the prediction of expected pain intensity. Repeating the analysis with either the optimism or the pessimism subscale did not alter the results. This finding indicated that one of the prerequisites for testing mediation was not fulfilled.

Although mediation analyses had to be ceased, both Pearson correlations (Table 1) and regression analyses as described above showed dispositional optimism and expected pain to be significantly related to experienced

\footnotetext{
${ }^{2}$ Bivariate correlation analyses were repeated in the group of participants who did not reach the $300 \mathrm{~s}$ tolerance limit and also for men and women separately, resulting in a comparable pattern of correlations. Additionally, no significant sex difference in optimism scores was found using an independent samples $t$ test. These results indicate that maxing out the immersion time or an even sex distribution might not alter the results in a significant manner.
} 
Table 1 Mean, standard deviation, range and intercorrelations of the main variables of Study 1

\begin{tabular}{|c|c|c|c|c|c|c|c|c|c|c|c|}
\hline & \multirow[t]{2}{*}{$M$} & \multirow[t]{2}{*}{$S D$} & \multirow[t]{2}{*}{ Range } & \multicolumn{8}{|c|}{ Correlations } \\
\hline & & & & 1 & 2 & 3 & 4 & 5 & 6 & 7 & 8 \\
\hline 1. Dispositional optimism & 21.71 & 3.87 & $12-29$ & - & & & & & & & \\
\hline 2. Optimism subscale & 10.00 & 2.16 & $5-14$ & $.86^{* *}$ & - & & & & & & \\
\hline 3. Pessimism subscale & 6.29 & 2.31 & $3-12$ & $-.88 * *$ & $-.51 * *$ & - & & & & & \\
\hline 4. Fear of pain & 43.91 & 9.66 & $29-81$ & -.19 & -.12 & .20 & - & & & & \\
\hline 5. Expected pain & 50.29 & 20.78 & $0-82$ & -.05 & -.09 & -.01 & .12 & - & & & \\
\hline 6. Pain during immersion & 52.41 & 22.03 & $10-95$ & $-.28^{*}$ & -.18 & $.30^{*}$ & .08 & $.31 *$ & - & & \\
\hline 7. Pain end immersion & 61.93 & 22.81 & $10-100$ & -.21 & -.08 & .03 & .03 & $.30 *$ & $.56 * *$ & - & \\
\hline 8. Pain post immersion & 42.53 & 24.92 & $0-95$ & -.15 & -.10 & .16 & -.12 & $.31 *$ & $.41 * *$ & $.65^{* *}$ & - \\
\hline 9. Tolerance time (seconds) & 195.29 & 108.13 & $23-300$ & -.03 & -.11 & -.12 & -.12 & -.12 & $-.46^{* *}$ & $-.62 * *$ & $-.29 *$ \\
\hline
\end{tabular}

$* p<.05 ; * * p<.001$

pain intensity. Hence we further explored the relative contribution of dispositional optimism, fear of pain, and expected pain to pain intensity ratings by means of regression analyses in which all independent variables were simultaneously entered as predictors of the different outcome variables. Results of these regression analyses are summarized in Table 2. As explained above, pain tolerance was added as a control variable in the analyses of pain intensity ratings at the end of immersion and post-immersion. Expected pain was significantly associated with all pain intensity ratings. Dispositional optimism contributed significantly to the prediction of pain intensity during and at the end of the immersion.

Additional subscale analyses pointed out that the pessimism subscale $(\beta=.30 ; t=2.59 ; p<.05)$ contributed significantly to the prediction of pain intensity during

Table 2 Result of regression analyses with dispositional optimism, fear of pain and expected pain as predictors of experienced pain in Study 1

\begin{tabular}{llrrr}
\hline Dependent variable & Predictor & $\beta$ & \multicolumn{1}{l}{$t$} & $p$ \\
\hline Pain during immersion & & & \\
$R^{2}=.17$ & Dispositional optimism & -.27 & -.23 & .03 \\
$F(3,62)=4.14$ & Fear of pain & -.00 & -.03 & .97 \\
$p=.007$ & Expected pain & .30 & 2.56 & .01 \\
Pain end immersion & & & & \\
$R^{2}=.50$ & Dispositional optimism & -.24 & -2.63 & .01 \\
$F(4,61)=15.17$ & Fear of pain & -.12 & -1.30 & .20 \\
$p<.001$ & Expected pain & .23 & 2.49 & .02 \\
& Tolerance time & -.61 & -6.68 & .00 \\
Pain post immersion & & & & \\
$R^{2}=.23$ & Dispositional optimism & -.19 & -1.64 & .11 \\
$F(4,61)=4.50$ & Fear of pain & -.22 & -1.90 & .06 \\
$p=.003$ & Expected pain & .29 & 2.55 & .01 \\
& Tolerance time & -.29 & -2.53 & .01 \\
\hline
\end{tabular}

immersion, together with expected pain $(\beta=.32$; $t=2.72 ; p<.05)$. In the prediction of pain intensity at the end of the immersion, the pessimism subscale $(\beta=.28$; $t=3.04 ; p<.01)$ was significant together with pain tolerance time $(\beta=.59 ; t=-6.56 ; p<.01)$ and expected pain $(\beta=.25 ; t=2.73 ; p<.05)$. The optimism subscale did not contribute significantly to the prediction of any of the outcome variables.

\section{Discussion}

This study was designed to test a mediation model in which pain-specific expectations were hypothesized to account for the relation between dispositional optimism and pain. Both dispositional optimism and expected pain intensity were significantly related to experienced pain intensity during a cold pressor task. When analyses were repeated for the optimism and pessimism subscales of the Life Orientation Test, only the pessimism subscale showed a significant association with experienced pain. In contrast to what would be expected, fear of pain did not correlate with any of the outcome variables. Pain tolerance (although technically only measured in participants who did not reach the $300 \mathrm{~s}$ limit) was not explained by any of our predictor variables.

Although this study corroborates that both dispositional optimism and low pain expectancies were significantly associated with lower pain ratings, the mediating role of pain-specific expectations in the optimism-pain relationship was not confirmed. It may be argued that dispositional optimism does not lead to more positive spontaneous pain expectations, but that it possibly interacts with induced expectations to determine the experience of pain (cf. Geers et al., 2005, 2010). Therefore, the second study was designed to test a moderation model. Pain-specific expectations were induced by means of verbal instructions about the cold pressor task, resulting in a group with high pain 
expectations and one with low pain expectations. It is hypothesized that the suggestion of low pain is especially beneficial in participants scoring high on dispositional optimism.

A relatively high percentage of participants reached the preset tolerance limit of $300 \mathrm{~s}$. Even though this is consistent with earlier reports (e.g. Chen et al., 1989), differences in pain tolerance may have influenced pain intensity ratings. Therefore in Study 2 participants were required to immerse their hand in the cold water container for a fixed period of $1 \mathrm{~min}$.

\section{Study 2}

Methods

\section{Participants}

Participants $\quad\left(N=60 ; \quad 36 \quad\right.$ female; $\quad M_{\text {age }}=21.83$; $S D=2.10$; Range $=19-30$ ) were recruited at Maastricht University. Volunteers received a financial compensation for their participation. Participants between 18 and 35 years were included if they did not participate in Study 1 . Other inand exclusion criteria were similar to those in Study 1.

\section{Apparatus and measures}

The cold pressor apparatus and trait questionnaires (i.e. LOT-R and FPQ-SF) were the same as in Study 1. Cronbach alpha values for LOT-R total score, optimism subscale, pessimism subscale and FPQ-SF in Study 2 are .67, $.39, .63$ and .86 respectively. Again pain-specific expectation was measured by a VAS and verbal ratings of pain intensity were made during, at the end and post-immersion.

\section{Procedure}

To conceal research purposes, students of Maastricht University were invited to participate in a test of what was called 'a new procedure of the cold pressor task'. Approval for the procedure was obtained from the institutional review board. At arrival in the lab all participants received general information about the study and provided informed consent. Participants were then randomised into one of two conditions: the 'low pain expectation' or the 'high pain expectation' group. In both conditions, additional instructions about the 'new cold pressor procedure' were used to manipulate pain expectations. In the 'high pain expectation' group, participants were told that the water in the container was colder than according to the usual procedure (close to $0{ }^{\circ} \mathrm{C}$ ). In the 'low pain expectation' group, participants were told that water temperature was warmer $\left(7 / 8^{\circ} \mathrm{C}\right)$. In reality, participants in both groups were exposed to the same temperature $\left(5^{\circ} \mathrm{C}\right)$. Participants were informed that the cold water immersion would have a duration of $1 \mathrm{~min}$. They subsequently immersed their hand in the room temperature container for $1 \mathrm{~min}$. Thereafter they indicated how painful they expected the cold pressor task to be on a VAS scale and immersed their hand in the cold water. Verbal pain reports were requested at 20 and $40 \mathrm{~s}$ (during immersion ratings) and at $60 \mathrm{~s}$ (end immersion rating). Immediately after this last rating, participants were instructed to extract their hand from the cold water container via the computer screen. After $20 \mathrm{~s}$, they provided the post-immersion pain intensity rating. At the end of the session participants filled in the LOT-R and FPQ-SF.

\section{Statistical analyses}

Independent samples $t$ tests were used to examine differences in age, dispositional optimism (total score), optimism/pessimism (subscales), fear of pain, expected and experienced pain ratings between the two conditions. Pearson correlation coefficients were calculated to explore the relations between the main variables.

The moderation hypothesis was tested following guidelines by Baron and Kenny (1986). Moderation was confirmed when the interaction term 'predictor $x$ moderator' was significant in the regression model whereby predictor, moderator and interaction term were simultaneously entered as predictors of the outcome variable. Continuous variables were centered prior to defining the interaction term. Regression analyses with expected and experienced pain ratings as outcome variables were conducted. Pain intensity ratings during $\left(20 \mathrm{~s}^{3}\right)$, at the end, and post-immersion were used separately as outcome variables to represent (different moments of) the total pain experience. Condition, dispositional optimism and fear of pain were entered in the first step and the interaction term 'condition $\times$ dispositional optimism' was entered in the second step of the regression analyses. Again, all regression analyses were repeated for the optimism and pessimism subscale.

Results

\section{Descriptive analyses and manipulation check}

Mean scores and standard deviations for the main variables of this study are presented in Table 3 . There were no significant differences between the groups on any of the variables except for the optimism subscale. Participants in the

\footnotetext{
${ }^{3}$ Identical to study 1 the rating at $20 \mathrm{~s}$ is reported as a measure of experienced pain during the immersion. Similar results were obtained when the $40 \mathrm{~s}$ ratings were analyzed.
} 
Table 3 Descriptives and differences of the main variables for the 'Low' and 'High pain expectation' group in Study 2

\begin{tabular}{|c|c|c|c|c|c|c|c|c|}
\hline & \multicolumn{3}{|c|}{ Low expectation group $(N=30)$} & \multicolumn{3}{|c|}{ High expectation group $(N=30)$} & \multirow[t]{2}{*}{$t$ value } & \multirow[t]{2}{*}{ Cohen's $d$} \\
\hline & $M$ & $S D$ & Range & $M$ & $S D$ & Range & & \\
\hline Age & 21.70 & 1.90 & $19-26$ & 21.97 & 2.34 & $19-30$ & -.49 & -.13 \\
\hline Dispositional optimism & 22.76 & 2.49 & $16-26$ & 21.30 & 3.39 & $12-28$ & 1.91 & .49 \\
\hline Optimism subscale & 10.73 & 1.68 & $7-14$ & 9.83 & 1.70 & $6-14$ & $2.06^{*}$ & .53 \\
\hline Pessimism subscale & 5.97 & 1.47 & $4-10$ & 6.53 & 2.05 & $4-12$ & -1.23 & -.31 \\
\hline Fear of pain & 42.30 & 10.25 & $26-63$ & 43.50 & 8.29 & $27-66$ & -.50 & -.13 \\
\hline Expected pain & 44.10 & 23.37 & $0-79$ & 58.57 & 21.19 & 0-91 & $-2.51^{*}$ & -.65 \\
\hline Pain during immersion & 37.63 & 20.89 & $10-70$ & 42.83 & 19.86 & $5-80$ & -.99 & -.26 \\
\hline Pain end immersion & 61.93 & 22.81 & 0-90 & 73.17 & 13.86 & $40-95$ & -2.31 & -.60 \\
\hline Pain post immersion & 42.53 & 24.92 & $5-90$ & 49.83 & 25.81 & $5-100$ & -1.11 & -.29 \\
\hline
\end{tabular}

$* p<.05$

Table 4 Correlation coefficients between the main variables of Study 2

\begin{tabular}{|c|c|c|c|c|c|c|c|}
\hline & 1 & 2 & 3 & 4 & 5 & 6 & 7 \\
\hline 1. Dispositional optimism & - & & & & & & \\
\hline 2. Optimism subscale & $.86^{* *}$ & - & & & & & \\
\hline 3. Pessimism subscale & $-.87 * *$ & $-.48 * *$ & - & & & & \\
\hline 4. Fear of pain & -.10 & -.01 & .17 & - & & & \\
\hline 5. Expected pain & -.02 & -.01 & .03 & .16 & - & & \\
\hline 6. Pain during immersion & -.02 & .06 & .13 & .01 & $.33 *$ & - & \\
\hline 7. Pain end immersion & $-.27 *$ & -.13 & $.34 * *$ & $.30 *$ & $.31 *$ & $.55^{* *}$ & - \\
\hline 8. Pain post immersion & $-.32 *$ & -.22 & $.32 * *$ & .19 & $.26^{*}$ & $.56^{* *}$ & $.71 * *$ \\
\hline
\end{tabular}

$* p<.05 ; * * p<.01$

low expectations group scored somewhat higher on this subscale. Supporting the effectiveness of the pain expectancy manipulation, expected pain intensity scores differed significantly between the 'low' and 'high' pain expectation group $(t=-2.51 ; p<.05)$. Pain intensity ratings as provided at the end of the immersion were significantly higher in the high pain expectancy group than in the low pain expectancy group. None of the participants withdrew their hand from the water before the end of the 1-min immersion period.

\section{Correlations}

Table 4 displays the Pearson correlation coefficients between dispositional optimism, optimism/pessimism subscales, fear of pain, expected and experienced pain intensity. Neither dispositional optimism, the optimism and pessimism subscales, nor fear of pain showed a significant correlation with expected pain intensity. Dispositional optimism was significantly related to pain intensity ratings at the end of the immersion and post-immersion. Subscale analyses showed that the pessimism but not the optimism subscale was related to the end of the immersion and post-immersion ratings. Fear of pain showed a significant correlation with the end immersion rating only. Expected pain correlated significantly with all three ratings of experienced pain. ${ }^{4}$

\section{Optimism, induced expectations and pain experience: examining moderation}

Regression analyses were conducted to examine the joint and independent predictive value of dispositional optimism, fear of pain, and condition on expected and experienced pain during, at the end and post-immersion. Table 5 presents the results of the regression analyses. For none of the outcome variables, the interaction between dispositional optimism and induced expectations accounted for a significant proportion of variance. Analyses were repeated for the two subscales separately. Neither the optimism nor pessimism subscale showed a significant

\footnotetext{
${ }^{4}$ Correlation analyses for the two conditions separately showed that the significance of the relations of optimism, fear of pain and painspecific expectations with pain intensity ratings is restricted to the high pain expectations group. Coefficients for both groups separately can be obtained upon request.
} 
Table 5 Results of regression analyses with dispositional optimism, fear of pain, condition and dispositional optimism $\times$ condition as predictors of experienced pain in Study 2

\begin{tabular}{|c|c|c|c|c|c|c|c|c|}
\hline Dependent Variable & Model & Variable entered & $R^{2}$ & $F$ & $p$ & $\beta$ & $t$ & $p$ \\
\hline \multirow[t]{7}{*}{ Expected pain } & \multirow[t]{3}{*}{1} & Dispositional optimism & \multirow[t]{3}{*}{.12} & \multirow[t]{3}{*}{2.64} & \multirow[t]{3}{*}{.06} & .07 & .55 & .58 \\
\hline & & Fear of pain & & & & .15 & 1.21 & .23 \\
\hline & & Condition & & & & .32 & 2.49 & .02 \\
\hline & \multirow[t]{4}{*}{2} & Dispositional optimism & \multirow[t]{4}{*}{.14} & \multirow[t]{4}{*}{2.20} & \multirow[t]{4}{*}{.08} & .24 & 1.08 & .28 \\
\hline & & Fear of pain & & & & .15 & 1.17 & .25 \\
\hline & & Condition & & & & .33 & 2.55 & .01 \\
\hline & & Dispositional optimism $\times$ Condition & & & & -.20 & -.94 & .35 \\
\hline \multirow[t]{7}{*}{ Pain during immersion } & \multirow[t]{3}{*}{1} & Dispositional optimism & \multirow[t]{3}{*}{.02} & \multirow[t]{3}{*}{.32} & \multirow[t]{3}{*}{.81} & -.01 & -.07 & .95 \\
\hline & & Fear of pain & & & & .00 & .01 & .99 \\
\hline & & Condition & & & & .13 & .92 & .36 \\
\hline & \multirow[t]{4}{*}{2} & Dispositional optimism & \multirow[t]{4}{*}{.02} & \multirow[t]{4}{*}{.26} & \multirow[t]{4}{*}{.90} & -.08 & -.33 & .74 \\
\hline & & Fear of pain & & & & .00 & .03 & .98 \\
\hline & & Condition & & & & .12 & .89 & .38 \\
\hline & & Dispositional optimism $\times$ Condition & & & & .08 & .36 & .72 \\
\hline \multirow[t]{7}{*}{ Pain end immersion } & \multirow[t]{3}{*}{1} & Dispositional optimism & \multirow[t]{3}{*}{.19} & \multirow[t]{3}{*}{4.53} & \multirow[t]{3}{*}{.01} & -.19 & -1.53 & .13 \\
\hline & & Fear of pain & & & & .26 & 2.18 & .03 \\
\hline & & Condition & & & & .23 & 1.83 & .07 \\
\hline & \multirow[t]{4}{*}{2} & Dispositional optimism & \multirow[t]{4}{*}{.23} & \multirow[t]{4}{*}{4.08} & \multirow[t]{4}{*}{.01} & -.25 & -1.93 & .06 \\
\hline & & Fear of pain & & & & .27 & 2.27 & .03 \\
\hline & & Condition & & & & .21 & 1.73 & .09 \\
\hline & & Dispositional optimism $\times$ Condition & & & & -.19 & 1.54 & .13 \\
\hline \multirow[t]{7}{*}{ Pain post immersion } & \multirow[t]{3}{*}{1} & Dispositional optimism & \multirow[t]{3}{*}{.13} & 2.76 & .05 & -.29 & -2.21 & .03 \\
\hline & & Fear of pain & & & & .15 & 1.22 & .23 \\
\hline & & Condition & & & & .07 & .51 & .61 \\
\hline & 2 & Dispositional optimism & .14 & 2.20 & .08 & -.42 & -1.92 & .60 \\
\hline & & Fear of pain & & & & .16 & 1.25 & .22 \\
\hline & & Condition & & & & .06 & .44 & .66 \\
\hline & & Dispositional optimism $\times$ Condition & & & & .16 & .77 & .45 \\
\hline
\end{tabular}

interaction with induced expectations. Therefore the interaction terms were removed from the model.

When considering main effects (step 1), condition was the only significant predictor of expected pain intensity. In addition, condition showed a trend towards significance in the prediction of experienced pain at the end of the immersion. Dispositional optimism significantly predicted pain intensity post-immersion, whereas fear of pain was a significant predictor of pain intensity at the end of the immersion. Repeating the analyses with the optimism and pessimism subscales demonstrated that the pessimism subscale significantly predicted pain intensity at the end of immersion $(\beta=.26$, $p<.05)$ and post-immersion $(\beta=.29, p<.05)$. The optimism subscale was not related to the outcomes.

\section{Discussion}

The second study was designed to test the hypothesis that dispositional optimism moderates the relation between induced pain expectations (high versus low) and expected as well as experienced pain intensity. In line with previous work (Arntz \& Claassens, 2004; Arntz et al., 1990; Vlaeyen et al., 2009), manipulation of pain-specific expectations using verbal instructions about the pain task was successful. However, dispositional optimism did not moderate the effect of induced expectations on expected or experienced pain. As in Study 1, results demonstrated that both pain-specific expectations and dispositional optimism correlate with pain intensity experienced in a cold pressor task. Dispositional optimism (and more specifically the pessimism subscale) significantly predicted post-immersion pain reports, over and above the influence of other variables. Pain intensity at the end of immersion was predicted by fear of pain and the pessimism subscale of the LOT-R. Although the current study did not provide support for the moderating effect of optimism on the influence of induced pain expectations, the results again demonstrated a significant association between both generalized and pain-specific expectations and the pain experience. 


\section{General discussion}

Two studies examined the associations of dispositional optimism and pain-related expectations with pain tolerance and experienced pain intensity in healthy participants undergoing a cold pressor task. The following conclusions can be derived from the present findings. Firstly, the role of pain-related expectations in the pain experience was established once more. Secondly, dispositional optimism was independently related to experienced pain intensity in both studies, thereby confirming the hypothesized relation between dispositional optimism and pain. Analyses with the optimism and pessimism subscales separately indicated that this association was mainly driven by the pessimism subscale. Finally, the results failed to support our hypothesized mediation and moderation models explaining the association amongst dispositional optimism, pain-specific expectations and pain sensitivity.

These studies add to the bulk of literature on the relation between pain-related expectations and reports of experienced pain (Devine \& Spanos, 1990; Keltner et al., 2006). In both studies, pain-specific expectations-both spontaneous and induced-correlated significantly with verbal pain ratings and this appeared to be independent from dispositional optimism and fear of pain.

The key variable of interest in this study was dispositional optimism, which has repeatedly been ascribed painprotective characteristics (Costello et al., 2002; Geers et al., 2008; Novy et al., 1998; Sipila et al., 2006). In line with the literature, both studies demonstrated that dispositional optimism as indexed by the LOT-R total score is related to pain intensity ratings. It should be noted however that dispositional optimism predicted reported pain during and at the end of the immersion in the first study and postimmersion in the second study. Possibly procedural and task-specific differences, as discussed below, might have contributed to this difference. Nevertheless, the significant effect of dispositional optimism on reported pain was consistently found in both studies. Interestingly, we found this relation despite controlling for fear of pain or painspecific expectations.

Since both subscales of the Life Orientation Test have been ascribed differential predictive value, all the analyses were repeated for the optimism and pessimism subscales. The observation that pessimism is more strongly associated with health outcomes (Brenes et al., 2002; RobinsonWhelen et al., 1997) was confirmed by our data. Only the pessimism subscale contributed to the overall effect of dispositional optimism on experienced pain. This finding stresses the importance of investigating whether positive and/or negative outcome expectancies are accountable for the relation of dispositional optimism with several (healthrelated) outcome measures. Moreover, optimism and pes- simism might be differentially related to certain underlying mechanisms of the dispositional optimism-pain link. A study by Ramirez-Maestre et al. (2012b) found that optimism and pessimism (subscales) lead to better adjustment in pain patients, through the use of active versus passive coping strategies respectively.

Both studies controlled for the influence of fear of pain, a known determinant of expected and experienced pain. Unexpectedly, fear of pain was not related to experienced pain or pain tolerance in Study 1. In line with prior research (Arntz et al., 1990; Leeuw et al., 2007; McCracken et al., 1993; Vlaeyen \& Linton, 2000), fear of pain was significantly related to experienced pain in the second study.

The present studies were specifically designed to investigate the role of pain-specific expectations in the relation between dispositional optimism and pain. In the first study, a mediation model was tested in which it was hypothesized that higher levels of dispositional optimism would translate into less negative pain expectations, resulting in lower experienced pain and higher pain tolerance in a cold pressor task. Surprisingly, dispositional optimism did not correlate significantly with specific expectations about cold pressor pain, disconfirming the hypothesized mediation model. Study 2 tested a moderation model in which dispositional optimism was expected to interact with induced expectations. The importance of the interaction of more stable characteristics and situational factors was argued before in studies describing the influence of dispositional optimism on placebo or nocebo responding (Geers et al., 2005, 2007, 2010). Results of the second study show that dispositional optimism does not moderate the relation between induced expectations and expected and experienced pain. In conclusion, neither the mediation nor the moderation model were supported. Although on theoretical grounds one would expect that global positive expectations would translate into positive expectations towards specific situations (in this case a pain situation), research in other domains have cautioned against comparing generalized and situational expectations (Klein \& Zajec, 2008). It has been argued that optimistic expectations are expressed strategically, being more extreme in situations in which the risk of disconfirmation is low (Armor \& Taylor, 1998). It could be speculated that a painful situation is a situation in which the risk of disconfirmation of optimistic expectations is considered too high. These findings suggest that alternative explanations should be considered for a better understanding of the optimism-pain link.

One of the possible underlying mechanisms, repeatedly related to optimism, is coping with stress and pain (Scheier \& Carver, 1985; Solberg Nes \& Segerstrom, 2006). The tendency of optimists to cope in a more active and less avoidant manner as well as optimists' flexibility in dealing 
with stressors, have been related to general well-being. Dispositional optimism has also been related to more adaptive pain coping (Geers et al., 2008; Novy et al., 1998; Ramirez-Maestre, et al., 2012b). Optimism was shown to be positively related to for instance the coping strategies diverting attention and behavioral activity and negatively to pain catastrophizing (Bargiel-Matusiewicz \& Krzyszkowska, 2009). These coping strategies, in turn predicted better adjustment to chronic pain (Ramirez-Maestre et al. 2012b).

Another candidate mechanism, also described in placebo literature, is cognitive reappraisal (Wiech et al., 2008). Possibly, optimistic people expect as much pain as less optimistic people, but they may attach another meaning to the pain. The translation of generalized positive outcome expectancies into pain-specific expectations might not be in terms of lower expected pain intensity. It could be that optimists reappraise pain or that they find benefits in a painful situation instead of dwelling on the negative consequences.

One might also argue that the relation between dispositional optimism and pain could be the result of a selfreport bias in optimists. Higher effect sizes are typically found for the relation of optimism with subjective as compared to objective health measures (Rasmussen et al., 2009). However, significant relations of optimism with objective measures such as immune functioning or psychophysiological measures have been reported (Costello et al., 2002; Segerstrom, 2005). Moreover, Geers et al. (2008) discarded individual differences in self-representational bias as an explanation for the relation between optimism and pain sensitivity by demonstrating that scores on the public self-awareness scale were not predictive of cold pressor pain.

Some limitations of the present studies may be noted. First of all, procedural differences between the two studies may limit a direct comparison of their results. For instance, immersion with tolerance measurement versus a fixed 1-min immersion and measurement of expected pain intensity before versus after the immersion in the room temperature container, might have contributed to an asymmetry between the results of both studies. Furthermore, in both studies optimism and fear of pain were measured after completion of the cold pressor task. Although trait measures were used to measure dispositional optimism and fear of pain, it cannot be excluded that the cold pain experience might have influenced the level of reported optimism and fear of pain. Furthermore, a larger sample size would possibly have added statistical power to the moderation analyses in Study 2. Additionally, these studies were conducted in a laboratory setting with healthy participants. It is unclear to what degree these results can be generalized to the daily experience of chronic pain, therefore replication in a clinical population is warranted. A last comment that needs to be made addresses the correlational approach that was applied in these studies. In examining the influence of optimism on the pain experience, manipulation of optimism is necessary to infer conclusions about the causal status of this personality trait.

In conclusion, the results of these two studies provide evidence for the association between dispositional optimism (in this case mainly driven by less negative outcome expectancies), pain-specific expectations, fear of pain (albeit to a lesser degree) and pain intensity during or after a cold pressor task. Furthermore, the current findings suggest that pain-specific expectations do not mediate the relation between dispositional optimism and pain. Also, the interaction between optimism and induced expectations does not seem to explain differences in pain experience. Dispositional optimism and pain expectations seem to be independently associated with experimentally induced cold pressor pain. Further research should address the causal status of optimism, and in addition try to clarify the proposed mechanisms underlying the pain protective influence of optimism. Knowledge on the mechanisms of resilience can provide alternative starting points for specifically targeted clinical applications. Not only have resilience factors been related to less negative pain-related outcomes (i.e. Karoly \& Ruehlman, 2006; Ong et al., 2010; Wright et al., 2008), preliminary findings with interventions aimed at increasing resilience appear to be promising (Carson et al., 2005). Insight in mediating and moderating variables of resilient processes can help to further shape such interventions.

Acknowledgments We thank Astrid Dello, Sandra Nijsten and Ina Schabram for their valuable input in these studies and for their assistance in the data collection. This study was supported by a grant from the Netherlands Foundation of Scientific Research.

\section{References}

Achat, H., Kawachi, I., Spiro, A., 3rd, DeMolles, D. A., \& Sparrow, D. (2000). Optimism and depression as predictors of physical and mental health functioning: The Normative Aging Study. Annals of Behavioral Medicine, 22, 127-130.

Affleck, G., Tennen, H., Zautra, A., Urrows, S., Abeles, M., \& Karoly, P. (2001). Women's pursuit of personal goals in daily life with fibromyalgia: A value-expectancy analysis. Journal of Consulting and Clinical Psychology, 69, 587-596.

Armor, D. A., \& Taylor, S. E. (1998). Situated optimism: Specific outcome expectancies and self-regulation. In M. P. Zanna (Ed.), Advances in experimental social psychology (Vol. 30, pp. 309-379). New York: Academic Press.

Arntz, A., \& Claassens, L. (2004). The meaning of pain influences its experienced intensity. Pain, 109, 20-25.

Arntz, A., van Eck, M., \& Heijmans, M. (1990). Predictions of dental pain: The fear of any expected evil, is worse than the evil itself. Behaviour Research and Therapy, 28, 29-41. 
Asmundson, G. J., Bovell, C. V., Carleton, R. N., \& McWilliams, L. A. (2008). The Fear of Pain Questionnaire-Short Form (FPQSF): Factorial validity and psychometric properties. Pain, 134, 51-58.

Bargiel-Matusiewicz, K., \& Krzyszkowska, A. (2009). Dispositional optimism and coping with pain. European Journal of Medical Research, 14(Suppl 4), 271-274.

Baron, R. M., \& Kenny, D. A. (1986). The moderator-mediator variable distinction in social psychological research: Conceptual, strategic, and statistical considerations. Journal of Personality and Social Psychology, 51, 1173-1182.

Benedetti, F., Pollo, A., Lopiano, L., Lanotte, M., Vighetti, S., \& Rainero, I. (2003). Conscious expectation and unconscious conditioning in analgesic, motor, and hormonal placebo/nocebo responses. Journal of Neuroscience, 23, 4315-4323.

Brenes, G. A., Rapp, S. R., Rejeski, W. J., \& Miller, M. E. (2002). Do optimism and pessimism predict physical functioning? Journal of Behavioral Medicine, 25, 219-231.

Carson, J. W., Keefe, F. J., Lynch, T. R., Carson, K. M., Goli, V., Fras, A. M., et al. (2005). Loving-kindness meditation for chronic low back pain: results from a pilot trial. [Randomized Controlled Trial]. Journal of Holistic Nursing: Official Journal of the American Holistic Nurses' Association, 23, 287-304.

Chen, A. C., Dworkin, S. F., Haug, J., \& Gehrig, J. (1989). Human pain responsivity in a tonic pain model: psychological determinants. Pain, 37, 143-160.

Colloca, L., Sigaudo, M., \& Benedetti, F. (2008). The role of learning in nocebo and placebo effects. Pain, 136, 211-218.

Costello, N. L., Bragdon, E. E., Light, K. C., Sigurdsson, A., Bunting, S., Grewen, K., et al. (2002). Temporomandibular disorder and optimism: Relationships to ischemic pain sensitivity and interleukin-6. Pain, 100, 99-110.

Devine, D. P., \& Spanos, N. P. (1990). Effectiveness of maximally different cognitive strategies and expectancy in attenuation of reported pain. Journal of Personality and Social Psychology, 58, 672-678.

Geers, A. L., Helfer, S. G., Kosbab, K., Weiland, P. E., \& Landry, S. J. (2005). Reconsidering the role of personality in placebo effects: dispositional optimism, situational expectations, and the placebo response. Journal of Psychosomatic Research, 58, 121-127.

Geers, A. L., Kosbab, K., Helfer, S. G., Weiland, P. E., \& Wellman, J. A. (2007). Further evidence for individual differences in placebo responding: an interactionist perspective. Journal of Psychosomatic Research, 62, 563-570.

Geers, A. L., Wellman, J. A., Fowler, S. L., Helfer, S. G., \& France, C. R. (2010). Dispositional Optimism Predicts Placebo Analgesia. Journal of Pain.

Geers, A. L., Wellman, J. A., Helfer, S. G., Fowler, S. L., \& France, C. R. (2008). Dispositional optimism and thoughts of well-being determine sensitivity to an experimental pain task. Annals of Behavioral Medicine, 36, 304-313.

Karoly, P., \& Ruehlman, L. S. (2006). Psychological "resilience" and its correlates in chronic pain: findings from a national community sample. Pain, 123, 90-97.

Keltner, J. R., Furst, A., Fan, C., Redfern, R., Inglis, B., \& Fields, H. L. (2006). Isolating the modulatory effect of expectation on pain transmission: A functional magnetic resonance imaging study. Journal of Neuroscience, 26, 4437-4443.

Klein, B., \& Zajec, L. (2008). Imagining a rosy future: The psychology of optimism. In K. D. Markman, W. M. P. Klein, \& J. A. Suhr (Eds.), Handbook of imagination and mental simulation. New York: Psychology press.

Leeuw, M., Goossens, M. E., Linton, S. J., Crombez, G., Boersma, K., \& Vlaeyen, J. W. (2007). The fear-avoidance model of musculoskeletal pain: current state of scientific evidence. Journal of Behavioral Medicine, 30, 77-94.

Linton, S. J., \& Shaw, W. S. (2011). Impact of psychological factors in the experience of pain. Physical Therapy, 91, 700-711.

Lorenz, J., Hauck, M., Paur, R. C., Nakamura, Y., Zimmermann, R., Bromm, B., et al. (2005). Cortical correlates of false expectations during pain intensity judgments-a possible manifestation of placebo/nocebo cognitions. Brain, Behavior, and Immunity, 19, 283-295.

Mahler, H. I. M., \& Kulik, J. A. (2000). Optimism, pessimism and recovery from coronary bypass surgery: Prediction of affect, pain and functional status. Psychology, Health \& Medicine, 5, 347-358.

Mangelli, L., Gribbin, N., Buchi, S., Allard, S., \& Sensky, T. (2002). Psychological well-being in rheumatoid arthritis: Relationship to 'disease' variables and affective disturbance. Psychotherapy and Psychosomatics, 71, 112-116.

McCracken, L. M., Gross, R. T., Sorg, P. J., \& Edmands, T. A. (1993). Prediction of pain in patients with chronic low back pain: Effects of inaccurate prediction and pain-related anxiety. Behaviour Research and Therapy, 31, 647-652.

Mirsky, J. B. (2007). Expectancy and the placebo effect: How cognitive processing utilizes the rACC to alter the perception of pain. Mind Matters: The Wesleyan Journal of Psychology, 2, 19-28.

Morton, D. L., Watson, A., El-Deredy, W., \& Jones, A. K. (2009). Reproducibility of placebo analgesia: Effect of dispositional optimism. Pain, 146, 194-198.

Novy, D. M., Nelson, D. V., Hetzel, R. D., Squitieri, P., \& Kennington, M. (1998). Coping with chronic pain: Sources of intrinsic and contextual variability. Journal of Behavioral Medicine, 21, 19-34.

Ong, A. D., Zautra, A. J., \& Reid, M. C. (2010). Psychological resilience predicts decreases in pain catastrophizing through positive emotions. Psychology and Aging, 25, 516-523.

Powell, R., Johnston, M., Smith, W. C., King, P. M., Chambers, W. A., Krukowski, Z., et al. (2012). Psychological risk factors for chronic post-surgical pain after inguinal hernia repair surgery: A prospective cohort study. European Journal of Pain, 16, 600-610.

Ramirez-Maestre, C., Esteve, R., \& Lopez, A. E. (2012a). The path to capacity: Resilience and spinal chronic pain. Spine, 37, E251E258.

Ramirez-Maestre, C., Esteve, R., \& Lopez, A. E. (2012b). The role of optimism and pessimism in chronic pain patients adjustment. The Spanish Journal of Psychology, 15, 286-294.

Rasmussen, H. N., Scheier, M. F., \& Greenhouse, J. B. (2009). Optimism and physical health: A meta-analytic review. Annals of Behavioral Medicine, 37, 239-256.

Robinson-Whelen, S., Kim, C., MacCallum, R. C., \& Kiecolt-Glaser, J. K. (1997). Distinguishing optimism from pessimism in older adults: Is it more important to be optimistic or not to be pessimistic? Journal of Personality and Social Psychology, 73, 1345-1353.

Roelofs, J., Peters, M. L., Patijn, J., Schouten, E. G., \& Vlaeyen, J. W. (2004). Electronic diary assessment of pain-related fear, attention to pain, and pain intensity in chronic low back pain patients. Pain, 112, 335-342.

Scheier, M. F., \& Carver, C. S. (1985). Optimism, coping, and health: Assessment and implications of generalized outcome expectancies. Health Psychology, 4, 219-247.

Scheier, M. F., \& Carver, C. S. (1992). Effects of optimism on psychological and physical well-being: Theoretical overview and empirical update. Cognitive Therapy and Research, 16, 201-228.

Scheier, M. F., Carver, C. S., \& Bridges, M. W. (1994). Distinguishing optimism from neuroticism (and trait anxiety, self-mastery, 
and self-esteem): A reevaluation of the Life Orientation Test. Journal of Personality and Social Psychology, 67, 1063-1078.

Segerstrom, S. C. (2005). Optimism and immunity: do positive thoughts always lead to positive effects? Brain, Behavior, and Immunity, 19, 195-200.

Sipila, K., Ylostalo, P. V., Ek, E., Zitting, P., \& Knuuttila, M. L. (2006). Association between optimism and self-reported facial pain. Acta Odontologica Scandinavica, 64, 177-182.

Solberg Nes, L., \& Segerstrom, S. C. (2006). Dispositional optimism and coping: A meta-analytic review. Personality and Social Psychology Review, 10, 235-251.

Sturgeon, J. A., \& Zautra, A. J. (2010). Resilience: A new paradigm for adaptation to chronic pain. Current Pain and Headache Reports, 14, 105-112.

Vlaeyen, J. W., Hanssen, M., Goubert, L., Vervoort, T., Peters, M., van Breukelen, G., et al. (2009). Threat of pain influences social context effects on verbal pain report and facial expression. Behaviour Research and Therapy, 47, 774-782.

Vlaeyen, J. W., \& Linton, S. J. (2000). Fear-avoidance and its consequences in chronic musculoskeletal pain: a state of the art. Pain, 85, 317-332.

Vlaeyen, J. W., \& Linton, S. J. (2012). Fear-avoidance model of chronic musculoskeletal pain: 12 years on. Pain (in press).

Wiech, K., Ploner, M., \& Tracey, I. (2008). Neurocognitive aspects of pain perception. Trends in Cognitive Sciences, 12, 306-313.

Wright, L. J., Zautra, A. J., \& Going, S. (2008). Adaptation to early knee osteoarthritis: The role of risk, resilience, and disease severity on pain and physical functioning. Annals of Behavioral Medicine, 36, 70-80. 